\title{
Deformation source revealed from leveling survey in Jigokudani valley, Tateyama volcano, Japan
}

Kohei Hotta ${ }^{*} \mathbb{0}$, Shigekazu Kusumoto² ${ }^{2}$ Hidenori Takahashi ${ }^{3}$ and Yuichi S. Hayakawa ${ }^{4}$

\begin{abstract}
We modeled the vertical deformation detected from a leveling survey in Jigokudani valley, Tateyama volcano, central Japan. In Jigokudani valley, uplift of $4 \mathrm{~cm} /$ year was previously detected during the period from 2007 to 2010 by interferometric synthetic aperture radar (InSAR). To confirm whether this inflation has continued to present day, we have conducted leveling surveys in Jigokudani valley since 2015. Most bench marks showed a subsidence of up to $5.6 \mathrm{~cm}$ during the 4-year period from October 2016 to September 2020, while a bench mark located at the center of the leveling route uniquely showed an uplift of $1.6 \mathrm{~cm}$. We applied a dislocation source model to the deformation using a grid search method. A crack with a length of $650 \mathrm{~m}$, a width of $425 \mathrm{~m}$, a strike of $\mathrm{N} 18^{\circ} \mathrm{E}$ and a dip of $67^{\circ}$ is located at a depth of $50 \mathrm{~m}$ near the center of Jigokudani valley (Koya jigoku and the new fumarolic area) where higher activity has been observed recently. Closing of the crack of $59 \mathrm{~cm}$ yields a volume decrease of $163,000 \mathrm{~m}^{3}$. The closing direction of the crack is parallel to the line of old explosion craters (Mikurigaike and Midorigaike ponds) and corresponds to the current maximum compressive stress field in the region of the Hida Mountains, including Tateyama volcano. The deformation source of the previous period from 2007 to 2010 detected from InSAR was estimated to be at a depth of $50 \mathrm{~m}$ and a gas chamber was correspondingly found in an audio-frequency magnetotelluric (AMT) survey. The AMT survey also revealed that thermal fluid is accumulating from a magma chamber and the location of our crack is similar to uppermost part of the thermal fluid path. During the period from 2015 to 2016, the crack opened and the inflation stopped during the next 1 year period from 2016 to 2017. During the period from 2017 to 2020, the crack began closing, probably because of the increase in emissions of volcanic fluid or gas with the formation of a new crater at the western side of Jigokudani valley during the period from 2017 to 2018.
\end{abstract}

Keywords: Tateyama volcano, Midagahara volcano, Dislocation source model, Leveling survey, Temporal change

\footnotetext{
*Correspondence: hotta@sus.u-toyama.ac.jp

${ }^{1}$ Faculty of Sustainable Design, University of Toyama, Toyama 930-8555,

Japan

Full list of author information is available at the end of the article
} original author(s) and the source, provide a link to the Creative Commons licence, and indicate if changes were made. The images or other third party material in this article are included in the article's Creative Commons licence, unless indicated otherwise in a credit line to the material. If material is not included in the article's Creative Commons licence and your intended use is not permitted by statutory regulation or exceeds the permitted use, you will need to obtain permission directly from the copyright holder. To view a copy of this licence, visit http://creativecommons.org/licenses/by/4.0/. 

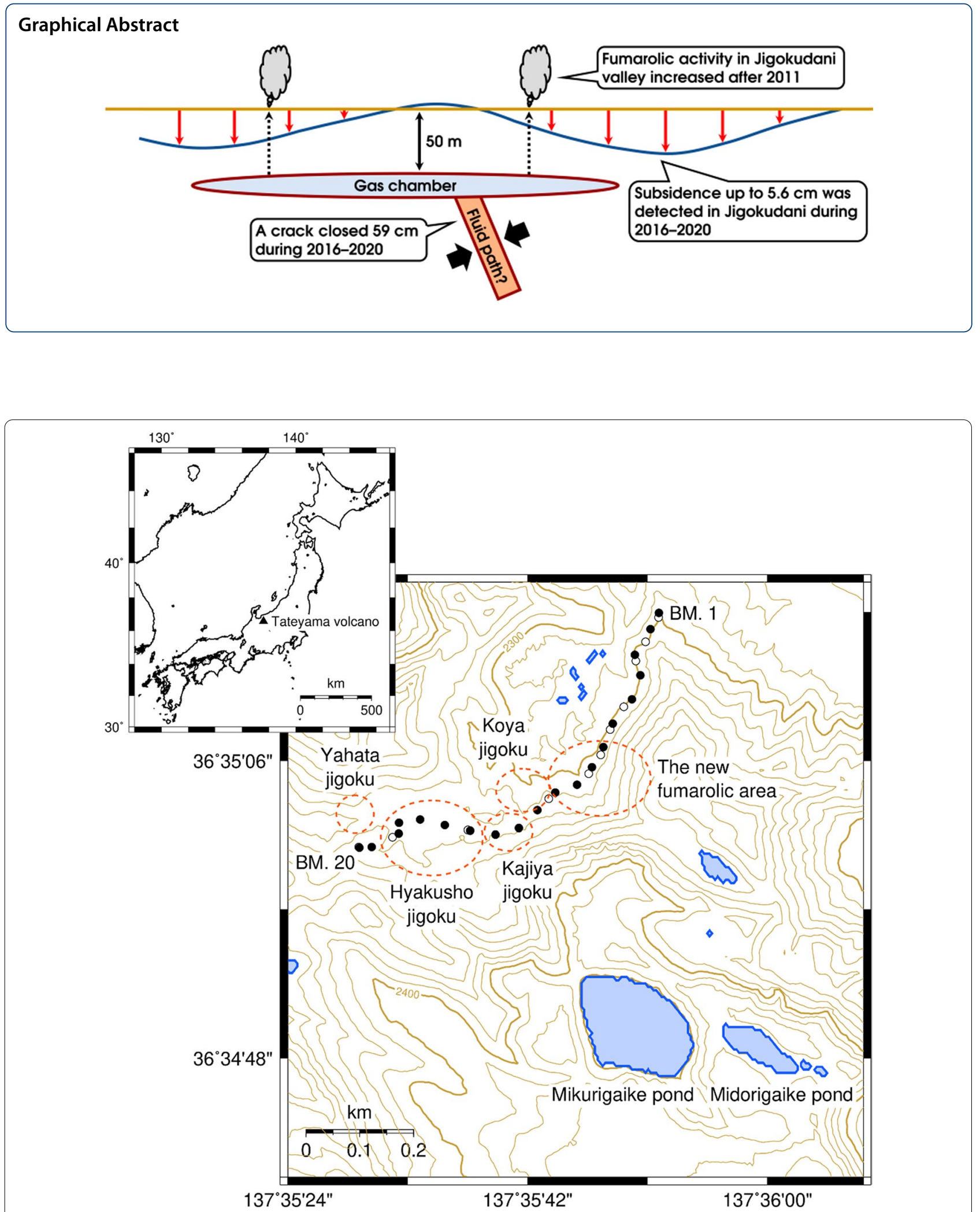

Fig. 1 (Upper left) Location map of Tateyama volcano (solid triangle). (Lower right) Enlarged map around Jigokudani valley (north area of the map). Open circles are remaining old leveling bench marks set in 2015 and solid circles are new leveling bench marks renewed in 2016. Ellipses with orange dashed lines represent fumarolic areas 


\section{Introduction}

Tateyama (or Midagahara) volcano is an andesitic volcano located in the Hida Mountains, central Japan (Fig. 1). Although this volcano has not experienced magmatic eruptions in historical times, at least four phreatic eruptions have occurred over the past 10,000 years (Kobayashi 1980). The last phreatic eruption is presumed to have occurred in 1836 (Nakano and Ito 1998). Such eruptions have created many craters, including Mikurigaike and Midorigaike ponds, with a WNW-ESE orientation. Currently, fumarolic activity is continuing in Jigokudani valley or "Jigokudani", meaning "hell valley" in Japanese, which was formed over approximately 40,000 years (Harayama et al. 2000). The fumarolic activity became violent in 2011, making the region around Jigokudani valley a keep-out area (Japan Meteorological Agency 2013). Before that, ground uplift of up to $4 \mathrm{~cm}$ /year was detected by interferometric synthetic aperture radar (InSAR) during the period from 2007 to 2010 (Kobayashi 2018). The deformation was revealed to have been caused by inflation of the deformation source at a depth of approximately $50 \mathrm{~m}$ from the surface (Kobayashi 2018). The deformation source was interpreted to correspond to the shallow gas chamber detected from the audio-frequency magnetotelluric (AMT) survey, which was found at a depth of approximately $50 \mathrm{~m}$ beneath Jigokudani valley (Seki et al. 2016). The AMT survey also revealed that thermal fluid is accumulating from a magma chamber at a depth of approximately $4 \mathrm{~km}$, which was estimated from a low-velocity seismic zone (Matsubara et al. 2000) toward the shallow gas chamber. After 2011 when the fumarolic activity level increased, significant deformation was no longer detected from InSAR due to accuracy limitations. To confirm whether this inflation has continued to the present, we have conducted leveling surveys in Jigokudani valley since 2015 . Since admittance to the valley is prohibited owing to the presence of volcanic gas, as mentioned above, we obtained permission from the Ministry of the Environment and used gas masks and protective goggles to ensure safety while conducting the surveys. The leveling surveys have been repeated every year and uplift or subsidence of several centimeters has been detected around active fumarolic areas of Hyakusho jigoku, Koya jigoku and the new fumarolic area (Fig. 1).

In the present study, we model and interpret vertical deformation during the period from 2016 to 2020 detected from leveling surveys. Then, we investigate and discuss the temporal change in inflation/deflation based on obtained source and previous leveling data, which has accumulated every year since 2015 .

\section{Observation}

Leveling surveys in Jigokudani valley have been conducted every year since 2015 by the University of Toyama. The leveling route in Jigokudani valley was set in 2015, but was renewed in 2016 because some bench marks were lost due to corrosion by volcanic gases. The locations of benchmarks are shown in Fig. 1. We used Leica GFL-4S leveling staffs and a Leica Sprinter 250M auto level. To avoid seasonal changes in leveling data, the leveling surveys were conducted in autumn (September or October) every year. We assumed the relative height of each benchmark and observation error with respect to BM. 1 using the least squares method of net adjustment.

The change in relative height with respect to BM. 1 for each benchmark after 2016 is shown in Fig. 2. Observation errors are less than $0.21 \mathrm{~cm}$. Koya jigoku and the new fumarolic area (BM. 7-11) showed slight uplift during the period from 2016 to 2017, which subsequently turned into continuous subsidence. Hyakusho jigoku (BM. 14-20) showed continuous subsidence. The subsidence rates for both areas are not constant, but instead vary every year. Between these areas in Kajiya jigoku (especially BM. 12), continuous uplift was observed, except for the period from 2017 to 2018. Since BM. 2 showed abnormal subsidence that was different from other nearby benchmarks, probably due to the collapse of a concrete block where the benchmark is located, we excluded the data for this benchmark in the following analysis.

\section{Analysis and results}

\section{Deformation source and residual evaluation}

The relative vertical deformation with respect to BM. 1 during the period from October 2016 to September 2020 is shown in Fig. 2. Most benchmarks showed subsidence of up to $5.6 \mathrm{~cm}$ during the 4 year period.

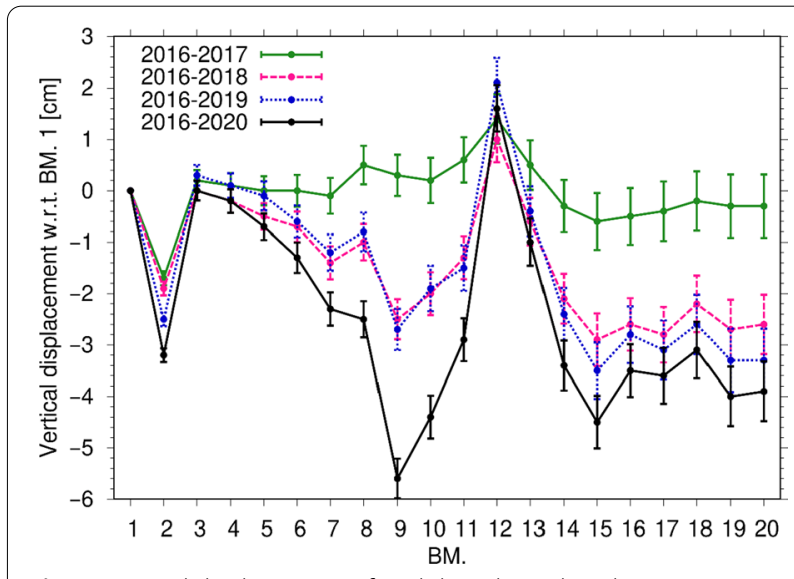

Fig. 2 Vertical displacement of each bench mark with respect to BM. 1 during the periods of 2016-2017, 2016-2018, 2016-2019 and 2016-2020. Error bars are $3 \sigma$ 
BM. 12, which is located at the center of the leveling route, showed an uplift of $1.6 \mathrm{~cm}$, unlike the other benchmarks. The characteristics of the vertical deformation indicate a closing crack, i.e., both sides of the crack subside, whereas the area directly above the crack uplift. Therefore, we applied a dislocation source model (Okada 1992) to the detected vertical deformation. We used the weighted residual sum of squares (WRSS) to evaluate the residual, which is defined as:

$$
\text { WRSS }=\sum_{i}\left(\frac{U_{i}^{o b s}-U_{i}^{c a l}}{\sigma U_{i}^{o b s}}\right)^{2},
$$

where $U_{i}^{o b s}$ and $U_{i}^{c a l}$ are, respectively, the observed and calculated vertical displacement at BM. $i$ with respect to BM. 1 ; and $\sigma U_{i}^{o b s}$ is the observation error at BM. $i$. Since the Poisson's ratio of the ground for Jigokudani is currently unknown, we considered five values of $0.05,0.15$, 0.25, 0.35 and 0.45 (according to Gercek (2007), Poisson's ratio for most rocks ranges from 0.05 to 0.45 ). Assuming the surface to have a flat topography (we ignored topographical effects because the elevation difference within the leveling route is at most $26 \mathrm{~m}$ and can be approximated as flat), we searched for the optimal combination of north-south and west-east locations, depth, dip, strike, length, width and opening of the dislocation source model that minimize the WRSS value by a grid search method for each value of Poisson's ratio. We set the range and step of the grid for each parameter shown in Table 1.

Table 1 Search range and step for the model parameters and their optimal values with uncertainties (square brackets) for a Poisson's ratio of 0.45

\begin{tabular}{llll}
\hline Parameter & Range & Step & Optimal value \\
\hline N-S location & $-1000-0 \mathrm{~m}$ & $25 \mathrm{~m}$ & $-325[-325,-325] \mathrm{m}$ \\
E-W location & $-1000-0 \mathrm{~m}$ & $25 \mathrm{~m}$ & $-650[-650,-650] \mathrm{m}$ \\
Depth from the surface & $0-500 \mathrm{~m}$ & $25 \mathrm{~m}$ & $50[50,75] \mathrm{m}$ \\
Length & $25-1000 \mathrm{~m}$ & $25 \mathrm{~m}$ & $650[625,675] \mathrm{m}$ \\
Width & $25-1000 \mathrm{~m}$ & $25 \mathrm{~m}$ & $425[150,1000] \mathrm{m}$ \\
Dip & $0-90^{\circ}$ & $1^{\circ}$ & $67[61,72]^{\circ}$ \\
Strike & $\mathrm{N} 0-359^{\circ} \mathrm{E}$ & $1^{\circ}$ & $\mathrm{N} 18[17,19]^{\circ} \mathrm{E}$ \\
Opening & $-500-500 \mathrm{~cm}$ & $1 \mathrm{~cm}$ & $-59[-74$ to -43$] \mathrm{cm}$ \\
\hline
\end{tabular}

The origin of the horizontal coordinate is BM. $1\left(137.597735^{\circ} \mathrm{E}, 36.58748187^{\circ}\right.$ $\mathrm{N})$. The uncertainties are the $99 \%$ confidence intervals estimated from an $F$-test (Árnadóttir and Segall 1994). The position is at the center of the top edge of the fault. The dip is clockwise from the horizontal, and the strike is clockwise from the north

\section{Results}

The minimum WRSS values for Poisson's ratios of 0.05 , $0.15,0.25,0.35$ and 0.45 are 178.50, 196.51, 259.15, 175.08 and 137.47, respectively. Therefore, we selected the combination of the optimal values for a Poisson's ratio of 0.45 . The obtained optimal values are shown in Table 1; and the location of the crack and a comparison of the observed and calculated vertical deformation are shown in Fig. 3. A crack with a length of $650 \mathrm{~m}$, a width of $425 \mathrm{~m}$ and a dip of $67^{\circ}$ is located at a depth of $50 \mathrm{~m}$ near Koya jigoku and the new fumarolic area, which has recently become highly activated. The strike of the crack is $\mathrm{N} 18^{\circ} \mathrm{E}$. The closing of the crack of $59 \mathrm{~cm}$ yields a volume decrease of $163,000 \mathrm{~m}^{3}$. The observed vertical deformation can be well explained by the obtained crack closure.

\section{Discussion}

The obtained crack is striking perpendicular to the line of Mikurigaike and Midorigaike lakes, which are old explosion craters. The compressive stress field in the WNWESE direction in this region (Mikumo et al. 1988) is accord with the alignment of explosion craters, such as the Mikurigaike and Midorigaike ponds. This direction is consistent with the crack closing direction. This compressive field might cause crack opening/closing in the WNW-ESE direction and the crack might be filled with

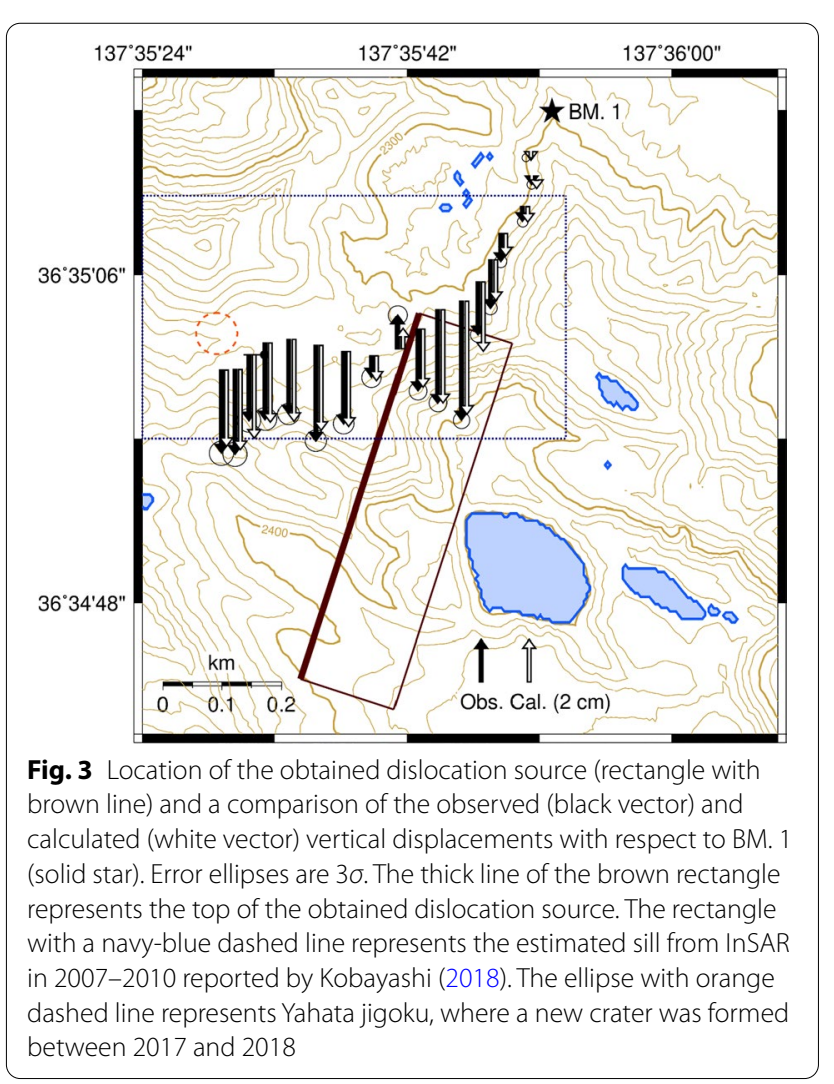


volcanic fluid or gas. The crack closed by $59 \mathrm{~cm}$ in total during the period from 2016 to 2020 due to recent active fumarole activities.

During the previous period from 2007 to 2010, a deformation source was found at a depth of $50 \mathrm{~m}$ using InSAR (Kobayashi 2018). The deformation source was interpreted to correspond to a gas chamber, which was found from AMT at a similar depth and location (Seki et al. 2016). The obtained crack, however, cannot explain the past inflation during 2007-2010 detected by InSAR. Opening of the crack causes ground uplift not only in the western side of the crack (inside Jigokudani where uplift was detected in 2007-2010), but also in the eastern side. The source obtained from a previous deformation is a sill at a depth of $50 \mathrm{~m}$. The estimated crack lies at deeper depths from 50 to $464 \mathrm{~m}(50[\mathrm{~m}]+450$ $[\mathrm{m}] \times \sin 67^{\circ}$ ). This might be because the inflation/deflation source during 2007-2010 and 2016-2020 is different. The sill identified by InSAR in 2007-2010 was interpreted as the shallow gas chamber found from the AMT survey by Seki et al. (2016) (Kobayashi 2018). The AMT survey also revealed that thermal fluid is accumulating from a magma chamber at a depth of approximately $4 \mathrm{~km}$, indicated by the presence of a low-velocity seismic zone (Matsubara et al. 2000) toward the shallow gas chamber. The location of the crack is similar to the uppermost part of the thermal fluid path. The current deformation of Jigokudani may be caused by the fluid path being deeper from 2007 to 2010 .

We applied the obtained crack to the previous vertical deformation for 1-year periods to investigate the temporal change in crack opening. The cumulative opening during the period from 2015 to 2020 is shown in Fig. 4a. The data for each 1-year period can be explained within a difference of approximately $1 \mathrm{~cm}$ by the estimated opening/closing (Fig. 4b). The crack opened (i.e., inflated) $9 \mathrm{~cm}$ during the period from 2015 to 2016 . Opening of the crack stopped during the next 1-year period from 2016 to 2017. Then the crack started closing between 2017 and 2018. The crack has continued closing (i.e., deflation) since then although the rate of closure varies from 2 to $33 \mathrm{~cm} /$ year. This deflation might be caused by an increase in fumarole activity due to the formation of a new crater at Yahata jigoku (northwest of BM. 17 and 18; Fig. 1) during the period from 2017 to 2018, and thus emission of volcanic fluid or gas may have increased since then. As a result, the crack, which may correspond to the uppermost part of the thermal fluid path and inflated until 2016, began deflating between 2017 and 2018 .

In the present study, we used the simple elastic model for the dislocation source reported by Okada (1992). However, plasticity or poroelasticity should be taken into account for more realistic modeling (e.g., Currenti et al. 2010). In addition, we used leveling data with only one component of the three-component displacement. We
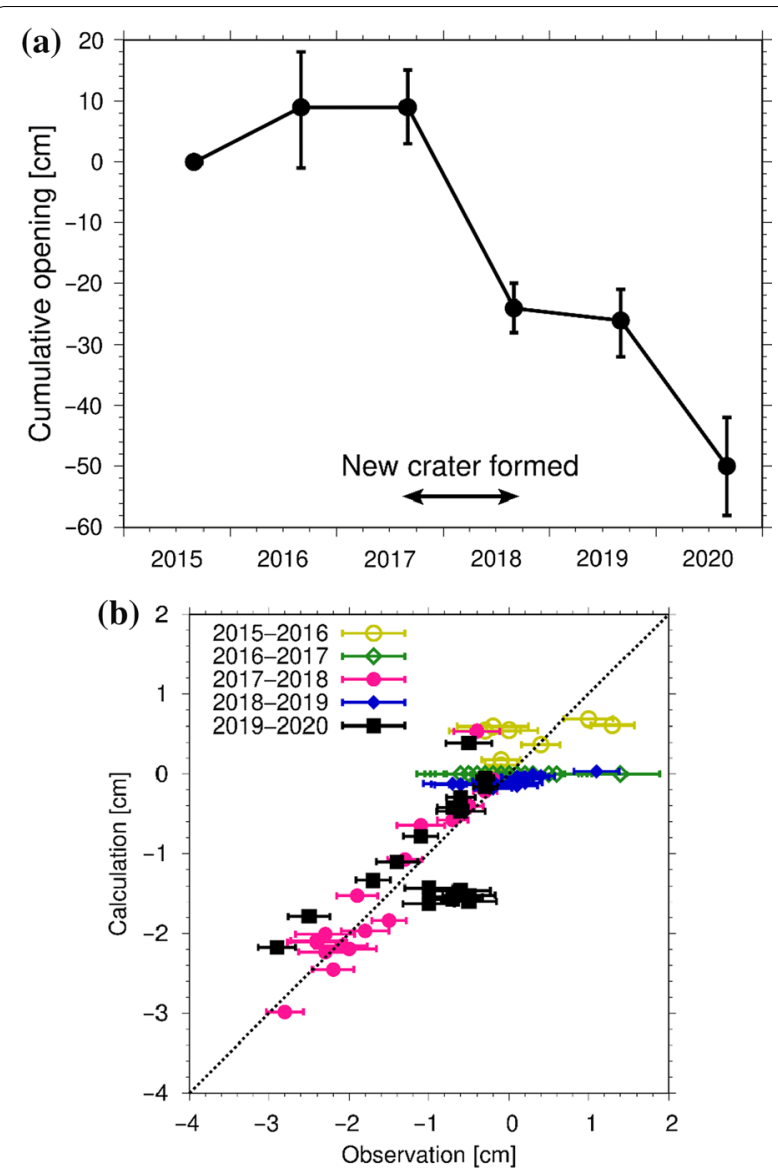

Fig. 4 a Cumulative opening of the crack during the period from 2015 to 2020. The cumulative opening is calculated from changes in volume over periods of 1 year (2015-2016, 2016-2017, 2017-2018, 2018-2019 and 2019-2020). Error bars are 99\% confidence intervals estimated from an F-test. b Comparison of observed and calculated vertical displacements with respect to BM. 1. Error bars are $3 \sigma$

started GPS observations in Jigokudani valley in 2020 . Three-dimensional displacement of GPS data will be taken into account in a future study.

\section{Conclusions}

From leveling surveys in Jigokudani valley, which have been conducted every year since 2015, uplift/subsidence of up to $3 \mathrm{~cm}$ per year was detected. A crack was identified at a depth of $50 \mathrm{~m}$ from the surface near Koya jigoku and the new fumarolic area where fumarolic activity is increasing. The crack may correspond to the uppermost part of the thermal fluid path. Due to emission of volcanic gas or fluid by violent fumarolic activity, the uppermost part of the thermal fluid path might have started deflating between 2017 and 2018 when a new crater was formed and continued until at least 2020, causing an increase in activity. 


\section{Abbreviations}

InSAR: Interferometric synthetic aperture radar; AMT: Audio-frequency magnetotelluric; WRSS: Weighted residual sum of squares.

\section{Acknowledgements}

Some figures in this paper were prepared using genetic mapping tools (Wessel et al. 2013) and the digital elevation model provided by the Geospatial Information Authority of Japan. Many students and/or graduate students at the University of Toyama helped with leveling surveys in Jigokudani valley. We are grateful to the Ministry of the Environment and Toyama Prefecture for allowing the installation of benchmarks. We appreciate Drs. Hickey and Sagiya and the two anonymous reviewers for their helpful comments.

\section{Authors' contributions}

$\mathrm{KH}$ contributed to the conception and design of the study; acquisition, analysis and interpretation of the data; and drafted the manuscript. SK contributed to the study conception and design; acquisition and analysis of data; and helped to draft the manuscript with critical revisions. HT and YH participated in the acquisition and analysis of data and helped to draft the manuscript. All authors read and approved the final manuscript.

\section{Funding}

The present study was supported by the Ministry of Education, Culture, Sports, Science and Technology of Japan, through its Earthquake and Volcano Hazards Observation and Research Program and by Japan Society for the Promotion of Science KAKENHI Grant Number 20 K05399.

\section{Availability of data and materials}

The datasets supporting the conclusions of this article are included within the article.

\section{Declarations}

\section{Competing interests}

The author declare that they havr no competing interests.

\section{Author details}

${ }^{1}$ Faculty of Sustainable Design, University of Toyama, Toyama 930-8555,

Japan. ${ }^{2}$ Institute for Geothermal Sciences, Graduate School of Science, Kyoto University, Beppu, Oita, Japan. ${ }^{3}$ Graduate School of Science and Engineering, University of Toyama, Toyama, Japan. ${ }^{4}$ Faculty of Environmental Earth Science, Hokkaido University, Sapporo, Hokkaido, Japan.

Received: 19 October 2021 Accepted: 7 February 2022

Published online: 18 February 2022

\section{References}

Árnadóttir T, Segall P (1994) The 1989 Loma Prieta earthquake imaged from inversion of geodetic data. J Geophys Res 99(B11):21835-21855. https:// doi.org/10.1029/94JB01256

Currenti G, Bonaccorso A, Negro CD, Scandura D, Boschi E (2010) Elastoplastic modeling of volcano ground deformation. Earth Planet Sci Lett 296:311-318. https://doi.org/10.1016/j.epsl.2010.05.013

Gercek H (2007) Poisson's ratio values for rocks. Int J Rock Mech Min Sci 44:1-13. https://doi.org/10.1016/j.jirmms.2006.04.011

Harayama S, Takahashi Y, Nakano S, Kariya Y, Komazawa M (2000) Geology of the Tateyama district. In: Geological Survey of Japan, p 218

Japan Meteorological Agency (2013) Japan meteorological agency, Midagahara. In: The National Catalogue of the Active Volcanoes in Japan (fourth ed.), p 1502

Kobayashi T (1980) The recent deposits of phreatic explosions in Tateyama volcano. Bull Volc Soc Japan 25(4):297 (in Japanese)

Kobayashi T (2018) Locally distributed ground deformation in an area of potential phreatic eruption, Midagahara volcano, Japan, detected by single-look-based InSAR time series analysis. J Volcanol Geoth Res 357(15):213-223. https://doi.org/10.1016/j.jvolgeores.2018.04.023

Matsubara M, Hirata N, Sakai S, Kawasaki I (2000) A low velocity zone beneath the Hida mountains derived from dense array observation and tomographic method. Earth Planets Space 52:143-154. https://doi.org/ 10.1186/BF03351623

Mikumo T, Wada H, Koizumi M (1988) Seismotectonics of the Hida region, central Honshu. Japan Tectonophys 147(1):95-119. https://doi.org/10. 1016/0040-1951(88)90150-3

Nakano S, Itoh J (1998) Eruption of Tateyama volcano. Bull Volc Soc Japan 43:123-126 (in Japanese)

Okada Y (1992) Internal deformation due to shear and tensile faults in a halfspace. Bull Seismol Soc Am 82:1018-1040

Seki K, Kanda W, Tanbo T, Ohba T, Ogawa Y, Takakura S, Nogami K, Ushioda M, Suzuki A, Saito Z, Matsunaga Y (2016) Resistivity structure and geochemistry of the Jigokudani valley hydrothermal system, Mt. Tateyama, Japan. J Volcanol Geotherm Res 325(1):15-26. https://doi.org/10.1016/j.jvolg eores.2016.06.010

Wessel P, Smith WHF, Scharroo R, Luis JF, Wobbe F (2013) Generic mapping tools: improved version released. EOS Trans Am Geophys Union 94:409-410. https://doi.org/10.1002/2013EO450001

\section{Publisher's Note}

Springer Nature remains neutral with regard to jurisdictional claims in published maps and institutional affiliations.

\section{Submit your manuscript to a SpringerOpen ${ }^{\circ}$ journal and benefit from:}

- Convenient online submission

- Rigorous peer review

- Open access: articles freely available online

- High visibility within the field

- Retaining the copyright to your article

Submit your next manuscript at $\boldsymbol{\nabla}$ springeropen.com 